\title{
ANALISIS SENTIMEN ONLINE REVIEW PENGGUNA BUKALAPAK MENGGUNAKAN METODE ALGORITMA TF-IDF
}

\author{
Pradita Eko Prasetyo Utomo*, Manaar, Ulfa Khaira, Tri Suratno \\ Fakultas Sains dan Teknologi, Universitas Jambi \\ email: pradita.eko@unja.ac.id
}

\begin{abstract}
Bukalapak is one of the Customer-To Customer $(C 2 C)$ e-commerce models. This model is the most widely applied and found on e-commerce sites in Indonesia. The Customer-To Customer $(C 2 C)$ market is currently still dominant in Indonesia's online retail market. Data collected from Euromonitor estimates that the C2C market contributed $3 \%$ of the retail market in Indonesia in 2017, while the B2C market contributed 1.7\%. One text mining analysis is that sentiment analysis can be applied to companies that issue a product or service and provide services to receive opinions (feedback) from consumers for the product. Sentiment analysis is applied to classify positive, negative, and neutral feedback from consumers so as to speed up and simplify the company's task to review their product deficiencies. The researcher conducted further analysis on Bukalapak user reviews to find out how user comments or opinions were on Bukalapak using the TF-IDF Algorithm method. And it can be concluded that based on customer review reviews in Bukalapak have a good rating or perception of this Vans shoe product. Can be seen from the results of Sentiments, Sentiment Visualization and WordCloud Visualization which shows that positive reviews have a higher frequency of $70 \%$.
\end{abstract}

Keywords: Sentiment Analysis, TF-IDF Algorithm, preprocessing, e-commerce, customers

\section{PENDAhuluan}

Indonesia telah menjadi pasar terbesar ecommerce di Asia Tenggara. Pada 2014, Euromonitor mencatat, penjualan online Indonesia mencapai US\$ 1,1 miliar, lebih tinggi dari Thailand dan Singapura. Namun, jka dibandingkan dengan total perdagangan retail, penjualan e-commerce di Indonesia hanya menyumbangkan 0,07 persen. Artinya, pasar e-commerce Indonesia berpeluang untuk tumbuh semakin besar. Apalagi dengan jumlah penduduk dan tingkat produk domestik bruto (PDB) terbesar di ASEAN. Euromonitor memperkirakan rata-rata pertumbuhan tahunan (CAGR) penjualan online Indonesia selama 2014- 2017 sebesar 38\% (Alexa, 2018).

Salah satu situs e-commerce terpopuler yang paling banyak dikunjungi di Indonesia menurut data per Oktober 2017-Januari 2018 adalah Bukalapak. Berdasarkan kunjungan ke situs Bukalapak berasal dari mesin pencari sebesar $34,30 \%$ dan total yang terhubung dengan situs Bukalapak sebesar 31.110.000 (DBS, 2017).

Bukalapak merupakan salah satu model e-commerce Customer-To Customer (C2C). Model ini yang paling banyak diterapkan dan di temukan pada situs e-commerce di Indonesia. Pasar Customer-To Customer (C2C) saat ini masih dominan di pasar ritel online Indonesia. Data yang dihimpun dari Euromonitor memperkirakan pasar $\mathrm{C} 2 \mathrm{C}$ menyumbangkan 3\% dari pasar ritel di Indonesia pada tahun 2017, sedangkan pasar B2C menyumbangkan 1,7\% (Euromonitor, 2017).

Selain itu juga masyarakat Indonesia lebih banyak memilih berbelanja online pada model $\mathrm{C} 2 \mathrm{C}$ karena banyak terdapat pilihan produk. Oleh sebab itulah pada penelitian ini akan menganalisis model C2C. Ulasan dari pengguna sering digunakan sebagai alat yang efektif dan efisien dalam menemukan informasi terhadap suatu produk atau jasa. Menurut Sung, bahwa penelitian baru-baru inimenemukan hampir 
$50 \%$ dari pengguna internet bergantung pada rekomendasi word-of-mouth (opini) sebelum menggunakan suatu produk, karena review dari pengguna lain dapat menyediakan informasi terbaru dari produk tersebut berdasarkan perspektif penggunapengguna lain yang sudah menggunakan produk tersebut (Fanani, F. 2017).

Tanggapan negatif maupun positif dari pengguna bisa jadi dipengaruhi oleh beberapa hal yang belum menjadi perhatian dari Bukalapak. Hal ini mungkin terjadi karena adanya beberapa faktor yang harus diperbaiki dan belum diketahui oleh Bukalapak. Dengan menggunakan text mining dapat dilihat pembicaraan apa saja yang sering dibahas oleh pengguna.

Salah satu analisis text mining yaitu analisis sentimen dapat diaplikasikan pada perusahaan yang mengeluarkan suatu produk dan jasa dan menyediakan layanan untuk menerima pendapat (feedback) dari konsumen untuk produk tersebut. Analisis sentimen untuk mengelompokan feedback positif, negatif, dan netral dari konsumen sehingga mempercepat dan mempermudah tugas perusahaan untuk meninjau kembali kekurangan produk mereka. Apabila ditemukan adanya sentiment negatif, maka perusahaan dapat dengan cepat mengambil tindakan untuk menanggulanginya.

Oleh sebab itu, dalam penelitian ini dilakukan analisis lebih lanjut mengenai ulasan pengguna Bukalapak untuk mengetahui bagaimana komentar atau opini pengguna terhadap Bukalapak. Berdasarkan alasan tersebut, maka dipilih menggunakan metode Algoritma TF-IDF.

\section{METODE PENELITIAN}

Data yang digunakan dalam penelitian ini adalah data ulasan atau komentar dari produk bukalapak, terkhususnya produk sepatu vans. Data di ambil menggunakan aplikasi Anaconda menggunakan library jupyter anaconda. Adapun untuk melakukan penelitian ini, metode analisis yang dilakukan adalah sebagai berikut:

1) Pengumpulan Data

Pada tahap ini, Pengumpulan data di lakukan dengan mengakses situs penjualan produk sepatu vans pada bukalapak dengan bantuan acses token agar lebih mudah mendapatkan review terhadap produk. Jumlah data yang di gunakan yaitu 300. Sebagai contoh, mengambil 10 data review pada Gambar 1.

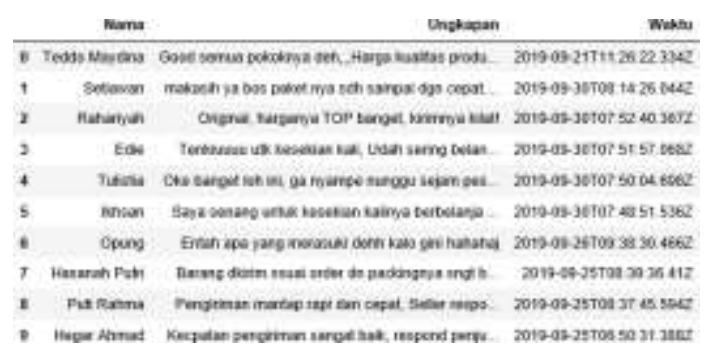

Gambar 1. Data Review Pelanggan

Dari data review tersebut akan dijadikan sample penelitian.

2) Prepocesssing Dataset (Pembersihan data) Pada tahap ini dilakukannya proses pembersihan data dimana dalam proses ini data yang diperoleh dalam bentuk teks dilakukan dengan menghilangkan punctuation, stopwords, spelling correction, tokenization, stemming, dilakukan perbaikan data dengan mengeliminasi data Missing Value. Kemudian melakukan suatu proses data sehingga mendapatkan atribut dan distribusi kelas yang relevan.

3) Analisis sentiment

Pada tahap ini, analisis sentimen dilakukan dengan Algoritma TF-IDF.

\section{HASIL DAN PEMBAHASAN}

a. Klasifikasi Data

Tahapan awal klarifikasi data yaitu preprocessing data. Berikut merupakan langkah yang di lakukan peneliti dalam proses preprocessing data:

1. Hilangkan Punctuation

Fungsi menghilangkan punctuation yaitu agar tidak mengganggu proses perhitungan dalam penerapan algoritma text mining. contohnya tanda baca dan karakter nonalfabet. Pada Gambar 2 ditampilkan hasilnya. 


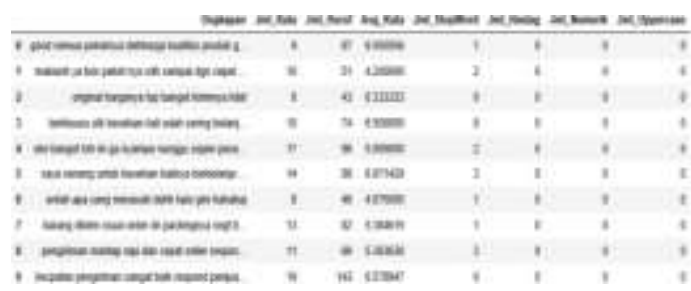

Gambar 2. Hasil punctuation

2. Hilangkan Stopword.

Fungsi menghilangkan stopword yaitu untuk menghilangkan kata kata yang tidak penting dalam data. Hasilnya ditunjukkan pada Gambar 3.

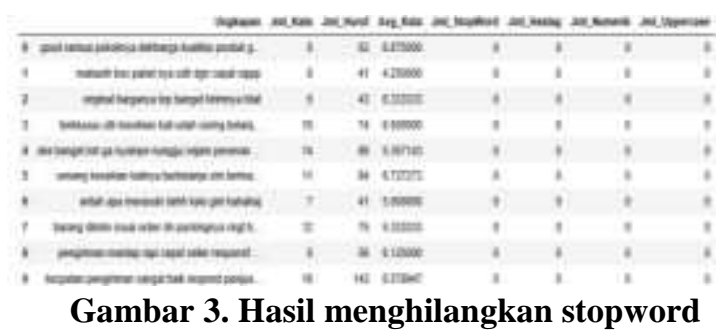

\section{Spelling Correction}

Fungsinya yaitu pengecekan ejaan dalam kata baik bahasa inggris maupun bahasa indonesia. Karena banyak kebiasaan user dalam menuliskan sebuah kata dengan menyingkatnya atau typo, jika penulisan singkatan atau typo tidak di perbaiki, ada kemungkinan besar dapat mempengaruhi hasil analisis akhirnya. Maka solusi mengatasi masalah ini dengan melakukan spelling correction. Hasilnya ditunjukkan pada Gambar 4.

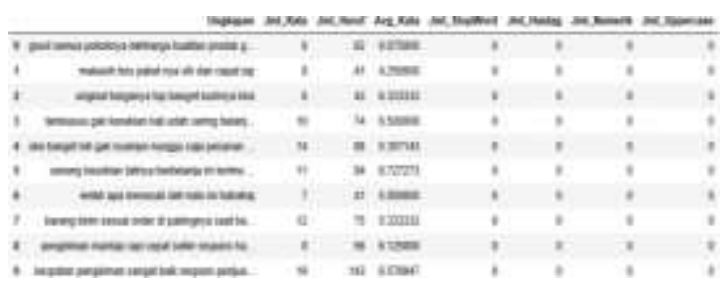

Gambar 4. Hasil Spelling Corection

\section{Tokenization}

Tokenization (tokenisasi) yaitu memecahkan kalimat menjadi bagianbagian kata. Hasil tokenisasi ditunjukkan pada Gambar 5.

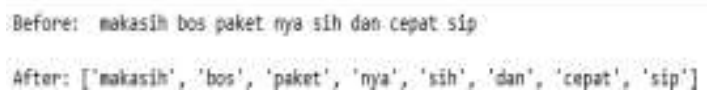

Gambar 5. Hasil Tokenization

\section{Stemming}

Stemming

bertujuan untuk mentransformasikan kata menjadi kata dasarnya atau kata baku. Yang menggunakan library Sastrawi untuk proses stemming bahasa Indonesia. Hasil dari proses stemming diperlihatkan pada Gambar 6.

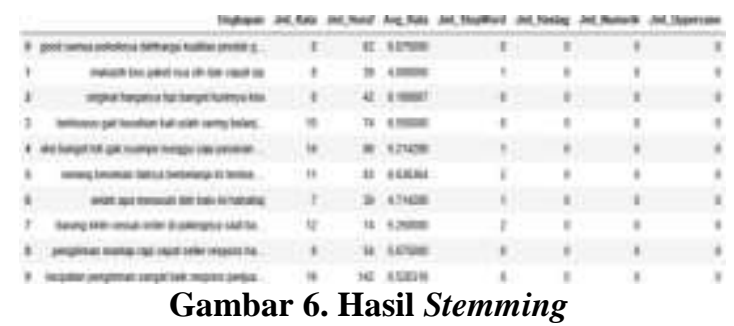

b. Algoritma TF-IDF

1. Term Frequency (TF)

Term Frequency adalah frekuensi kemunculan sebuah kata. Semakin besar nilai TF nya, maka semakin besar pula bobot nya. Hasil TF ditunjukkan pada Gambar 7.

\begin{tabular}{|c|c|c|}
\hline & Ka1a & Tam Frapuanse \\
\hline 14 & senet & 70 \\
\hline es & di & 6.0 \\
\hline 59 & tarang & $B O$ \\
\hline 7 & prostik. & 40 \\
\hline 67 & 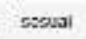 & 40 \\
\hline 74 & 8tinget & 4.8 \\
\hline 47 & ni & 40 \\
\hline 0 & tetaris & 4.6 \\
\hline a & makasis & 30 \\
\hline 25 & Mhiras & 30 \\
\hline
\end{tabular}

Gambar 7. Hasil Term Frequency

2. Inverse Document Frequency (IDF)

IDF menunjukkan hubungan ketersediaan sebuah term dalam seluruh dokumen. Semakin sedikit TF nya, maka nilai IDF semakin besar. Hasil IDF diperlihatkan pada Gambar 8.

\begin{tabular}{|c|c|c|c|}
\hline & Kata & Term Frequence: & IDE \\
\hline 14 & capat & 70 & 1734501 \\
\hline 65 & a & 5.0 & 2833213 \\
\hline sy & tarieng & 611 & 2घ5213 \\
\hline 7 & perodic: & 60 & 1223775 \\
\hline 87 & metsai & oll & $2 \mathrm{nsp} / \mathrm{s}$ \\
\hline 74 & $\operatorname{sangnt} 1$ & 40 & 2833213 \\
\hline 47 & ini & 40 & 2833213 \\
\hline " & betatian & 80 & $0 \times 50372$ \\
\hline a & makelh & 30 & 1734801 \\
\hline k & ithxan & 30 & $2 \mathrm{ascn}$ \\
\hline
\end{tabular}


Gambar 8. Hasil IDF

\section{Term Frequency - Inverse Document} Frequency (TF-IDF)

Algoritma TF-IDF (Term Frequency inverse Document Frequency) adalah salah satu algoritma yang digunakan untuk menganalisa hubungan antara sebuah kalimat dengan sekumpulan dokumen dan metode untuk menghitung bobot setiap kata yang paling umum di gunakan. Rumus umum untuk TF-IDF adalah penggabungan dari formula perhitungan raw $\mathrm{TF}$ dan formula IDF dengan cara mengalikan nilai Term Frequency (TF) dengan nilai Inverse Document Frequency (IDF) yang ditunjukkan pada persamaan (1). Serta hasil dari TF-IDF diperlihatkan pada Gambar 9.

$$
w_{i j}=t f_{i j} \times i d f_{j}
$$

\begin{tabular}{|c|c|c|c|c|}
\hline & Kata & Tearm Frequench & IDF & TFInF \\
\hline 14 & carat & 70 & 1730001 & 12142207 \\
\hline cos & $a$ & 5.0 & 2833213 & $16 . \operatorname{seg} 250$ \\
\hline 54 & bereg & 80 & 2832813 & 16989200 \\
\hline 7 & produk: & 40 & 1.223775 & 4.305102 \\
\hline 67 & sesua & 40 & 2833213 & 11332853 \\
\hline 74 & samzat & 40 & 2033213 & 11.332053 \\
\hline 47 & in & 40 & 2833213 & 11332853 \\
\hline e & teinga & 40 & 2753772 & $3.01508 ?$ \\
\hline a & makash & 30 & 1734601 & G S Xoanct \\
\hline 25 & ivaran & 30 & 2 a.33713 & R 4 Safito \\
\hline
\end{tabular}

Gambar 9. Hasil TF-IDF

4. Hasil Sentimen, Visualisasi Sentimen dan Visualisasi WordCloud

Hasil Analisis Sentimen ditunjukkan pada Gambar 10 dan Gambar 11 serta telah diberikan pelabelan ke dalam kelas sentimen positif, negatif, dan netral.

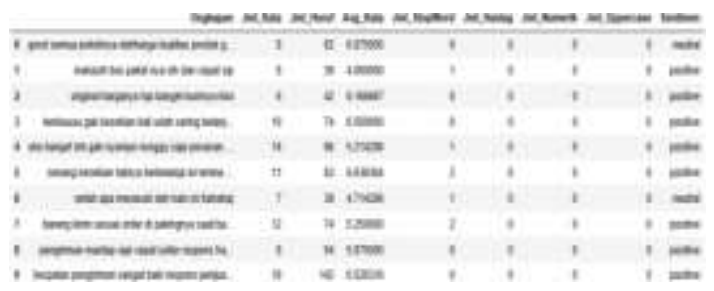

Gambar 10. Hasil Sentimen

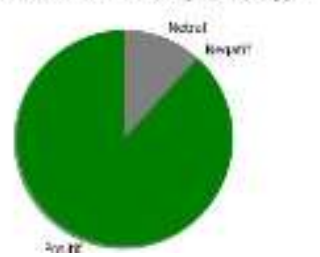

\section{Gambar 11. Hasil Visualisasi Sentimen}

Dari Gambar 11 dapat diketahui bahwa hasil pelabelan kelas sentimen menunjukkan bahwa jumlah ulasan positif memiliki frekuensi yang lebih tinggi dibandingkan dengan jumlah ulasan Netral, dan tidak memiliki ulasan Negatif dari 17 ungkapan pengguna.

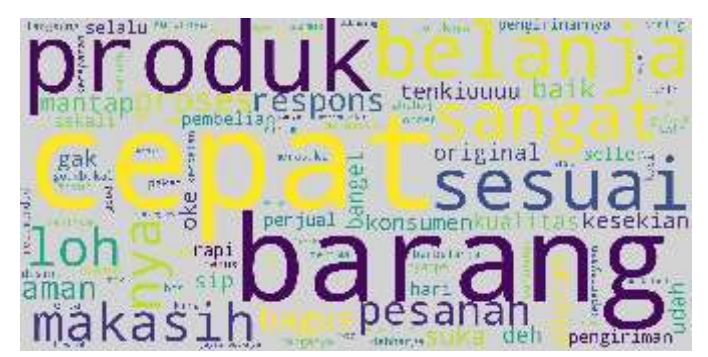

Gambar 12. Hasil Visualisasi WordCloud

Sementara itu dengan menggunakan Visualisasi Wordcloud yang ditunjukkan pada Gambar 12 memberikan gambaran yang lebih jelas tentang topik dan kata-kata positif yang sering digunakan pengguna Bukalapak dalam memberikan ulasan. Semakin besar ukuran kata pada wordcloud menggambarkan semakin tinggi pula frekuensi kata tersebut, artinya semakin sering pengguna menggunakan kata tersebut sebagai topik pembicaraan atau penilaian positif dalam ulasan. Beberapa topik yang sering di bahas pengguna Bukalapak diantaranya adalah cepat, barang, produk, sesuai, makasih, belanja,sangat dan sebagainya.

\section{KESIMPULAN}

Berdasarkan hasil analisis menggunakan algoritma TF-IDF dapat di simpulkan bahwa berdasarkan ulasan review pelanggan di bukalapak mempunyai penilaian ataupun presepsi yang baik terhadap produk sepatu ini. Dapat dilihat dari hasil Sentimen, Visualisasi Sentimen dan Visualisasi WordCloud yang menunjukkan bahwa ulasan positifnya memiliki frekuensi yang lebih tinggi yaitu $70 \%$.

\section{REFERENSI}

Alexa. 2018. Traffic Statictic Bukalapak. com. https://www.alexa.com/siteinfo /bukalapak.com. 
DBS. 2017. Indonesia Pusat E- commerce ASEAN. https://www.dbsinsights.com/ id/digital-dan-inovasi/indonesia-pusat-ecommerce- asean.

Euromonitor. 2017. Market Research Indonesia.http://www.euromonitor.co $\mathrm{m} /$ in donesia.

Fanani, F. 2017. Klasifikasi Review Software Pada Google Play Menggunakan Pendekatan Analisis Sentimen. Skripsi. Program Studi Teknologi Informasi Fakultas Teknik UGM Yogyakarta. 